\title{
PENELITIAN PENAMBAHAN BAHAN BATU PADAS PADA CAMPURAN ASPAL BETON
}

\author{
Supriadi ${ }^{* 1}$, Yosef Cahyo SP ${ }^{2}$, Ahmad Ridwan ${ }^{3}$, Agata Iwan Candra ${ }^{4}$. \\ ${ }^{1,2,3}$ Fakultas Teknik, Universitas Kadiri. \\ e-mail: ${ }^{* 1}$ arkedangsupri@gmail.com,2yosef.cs@unik-kediri.ac.id, \\ 3ahmad_ridwan@unik-kediri.ac.id, ${ }^{4}$ iwan_candra@unik-kediri.ac.id .
}

\begin{abstract}
Asphalt Concrete (Hotmix) is a mixture of coarse aggregate, fine aggregate, and filler (Filler) with asphalt binder in high-temperature conditions with the composition studied and regulated by technical specifications. In this study, asphalt concrete mixtures were given materials additional padas. This addition was carried out to study and determine the effect of padas on the asphalt concrete mixture with the addition of 5\%,10\%, and 15\%. Compressive strength specimens in the form of cylinders with a diameter of 10.09 $\mathrm{cm}$ and an average height of $7.8 \mathrm{~cm}$. Testing is done after 2 days. Asphalt, with the addition of 5\% padas, is better able to produce a better value of stability than others. The addition of padas rock produced a strong stability of $5 \%$ at $888.0747 \mathrm{~kg}, 10 \%$ at $598,199 \mathrm{~kg}, 15 \%$ at 441,6391 kg. To reach the optimum level, the mixture on concrete asphalt ranges $<5 \%$
\end{abstract}

Keywords: Padas Stone, Concrete Asphalt, Effect Of Padas Stone, Optimum Level

\begin{abstract}
Abstrak
Aspal Beton (Hotmix) adalah campuran agregat kasar, agregat halus, dan bahan pengisi (Filler) dengan bahan pengikat aspal dalam kondisi suhu tinggi (panas) dengan komposisi yang diteliti dan diatur oleh spesifikasi teknis.. Pada penelitian ini, campuran aspal beton diberi bahan tambahan batu padas. Penambahan ini dilakukan untuk mempelajari dan mengetahui pengaruh batu padas pada campuran aspal beton dengan penambahan $5 \%, 10 \%$, dan 15\%. Benda uji kuat tekan berupa silinder dengan diameter 10,09 $\mathrm{cm}$ dan tinggi rata rata $7,8 \mathrm{~cm}$. Pengujian dilakukan setelah 2 hari. Aspal dengan penambahan batu padas 5\% lebih mampu menghasilkan nilai stabilitas yang lebih baik dari pada yang lainya. Penambahan batu padas menghasilakan kuat stabilitas masing masing yaitu 5\% sebesar $888.0747 \mathrm{~kg}, 10 \%$ sebesar 598.199 $\mathrm{kg}, 15 \%$ sebesar $441.6391 \mathrm{~kg}$. Untuk mencapai kadar optimum maka campuran padas pada aspal beton berkisar antara $<5 \%$
\end{abstract}

Kata Kunci : $\quad$ Batu Padas, Aspal Beton, Pengaruh Batu Padas, Kadar Optimum 


\section{PENDAHULUAN}

Aspal beton sebagai bahan untuk konstruksi jalan sudah lama dikenal dan digunakan secara luas dalam pembuatan jalan, [1][2][3]. Penggunaannya pun di Indonesia dari tahun ke tahun makin meningkat. Hal ini disebabkan aspal beton mempunyai beberapa kelebihan dibanding dengan bahan-bahan lain, diantaranya harganya yang relatif lebih murah dibanding beton, kemampuannya dalam mendukung beban berat kendaraan yang tinggi dan dapat dibuat dari bahan-bahan lokal yang tersedia dan mempunyai ketahanan yang baik terhadap cuaca [4][5]. Aspal beton atau asphaltic concrete adalah campuran dari agregat bergradasi menerus dengan bahan bitumen, [6][7]. Kekuatan utama aspal beton ada pada keadaan butir agregat yang saling mengunci dan sedikit pada pasir/ filler / bitumen sebagai mortar. Pengalaman para pembuat aspal beton mengatakan bahwa campuran ini sangat stabil tetapi sangat sensitif terhadap variasi dalam pembuatannya dan perlu tingkat quality control yang tinggi dalam pembuatannya, bila potensinya ingin penuh terealisasi.

\section{METODE PENELITIAN}

\subsection{Perkerasan Jalan}

Perkerasan jalan direncanakan untuk memikul beban lalu lintas secara aman dan nyaman. Berdasarkan bahan pengikatnya konstruksi jalan dapat di bedakan atas : perkerasan lentur dan perkerasan kaku, [8][9][10].

\subsection{Laston $(A C)$}

Laston adalah suatu lapis permukaan yang terdiri dari campuran aspal keras sebagai bahan pengikat dan agregat kasar, halus, dan pengisi (filler), dengan cara pencampuran dan pemadatan dalam kondisi panas dan suhu tertentu, [11].

\subsection{Bahan Campuran Laston (AC)}

Untuk bahan campuran laston (AC) terdiri dari :

a. Aspal

Aspal adalah material hasil penaringan minyak mentah dan merupakan hasil dari industry perminyakan, [12][13].

b. Agregate

Agregat yang merupakan bahan utama untuk struktur jalan, adalah sekumpulan butir-butir batu pecah dan pasir, atau mineral yang lain, baik dari hasil alam, maupun buatan, [14][15].

\subsection{Bahan Pengisi (Filler)}

Bahan pengisi dapat terdiri atas debu batu padas, debu dolomite, semen Portland, abu 
terbang, debu tanur tinggi pembuat semen atau bahan mineral tidak plastis lainnya, [16].

\subsection{Bahan Bitumen}

Bitumen adalah zat perekat (cementitious) berwarna hitam atau gelap, yang dapat diperoleh di alam ataupun sebagai hasil produksi.

\subsection{Data Umum}

Jenis penelitian yang digunakan adalah jenis penelitian ekperimental. Penelitian pertama dilakukan untuk menguji kadar kuat stabilitas pada batu padas yang didapat dari kota Nganjuk. Setelah mendapatkan hasil yang sesuai SNI, maka dilanjutkan dengan pembuatan benda uji berbentuk silinder sebanyak 9 buah dengan penambahan kadar padas $5 \%, 10 \%, 15 \%$.[17][18]

\subsection{Pengujian Sample}

a. Bersihkan benda uji dari kotoran yang menempel serta beri nomor.

b. Ukur tinggi dan timbang berat benda uji

c. Rendam benda uji dalam air kira kira 24 jam pada suhu ruang tertutup.

d. Timbang benda uji dalam air untuk mendapatkan berat isi setelah itu keringkan benda uji dan timbang kembali.

e. Rendam benda uji kedalam bak perendam (waterbath) selama 20-40 menit pada suhu 600

f. Lakukan tes terhadap alat marshall, catat hasilnya

g. Menghitung parameter marshall, [19][20].

1. Unit weight

$\mathrm{Gmb}=\frac{W}{B}$

Dimana:

$\mathrm{Gmb}=$ Berat volume kering campuran $\left(\mathrm{gram} / \mathrm{cm}^{3}\right)$

$\mathrm{W} \quad=$ Berat benda uji di udara (gram)

B $\quad=$ Volume benda uji $\left(\mathrm{cm}^{3}\right)$

2. VIM (Voids In Mix)

$$
\begin{aligned}
& \mathrm{VIM}=\left[1-\frac{\text { Gse }}{B J \text { maax }}\right] \times 100 \% \\
& \text { Gse }=\frac{P m m-P b}{\frac{P m m}{B J \max }-\frac{P b}{G b}}
\end{aligned}
$$

Dimana: 


$$
\begin{array}{ll}
\mathrm{VIM} & =\text { Rongga udara terhadap campuran }(\%) \\
\mathrm{Gse} & =\text { Berat jenis efektif agregat } \\
\mathrm{Pmm} & =\text { Presentase berat total campuran }(=100) \\
\mathrm{BJ} \text { max } & =\text { Berat jenis maksimum campuran } \\
\mathrm{Pb} \quad & =\text { Kadar aspal } \\
\mathrm{Gb} & =\text { Berat jenis aspal }
\end{array}
$$

\section{Stability (stabilitas)}

Stability $=$ O x E' $\times$ Q

Dimana:

Stability $=$ Stabilitas Marshall

$\mathrm{O}=$ = Pembacaan arloji stabilitas (Lbf)

E' $\quad=$ Angka korelasi volume benda uji

Q $\quad=$ Kalibrasi alat Marshall

\section{Flow (kelelehan plastis)}

Nilai flow diperoleh dari pembacaan arloji kelelehan pada alat uji Marshall dan dinyatakan dalam satuan $\mathrm{mm}$.

\section{VMA (Voids in Mineral Aggregat)}

$$
\mathrm{VMA}=100-\frac{100-P b}{G s b} \times \mathrm{Gmb}
$$

Dimana:

VMA = Volume pori antara butir agregat di dalam beton aspal (\%)

$\mathrm{Gsb}=$ Berat jenis kering total agregat

$\mathrm{Gmb}=$ Berat volume kering campuran $\left(\mathrm{gram} / \mathrm{cm}^{3}\right)$

6. VFB (Voids Filled Bitument)

$\mathrm{VFB}=\frac{100(V M A-V I M)}{d V M A} \%$ dari VMA

Dimana:

VFB = Volume pori antara butir agregat yang terisi aspal

VMA = Volume pori antara butir agregat di dalam beton aspal padat $(\%)$

VIM = Volume rongga udara dalam campuran (\%)

\section{MQ (Marshall Quetiont)}


Nilai Marshall Quotient dihitung sebagai berikut:

$\mathrm{MQ}=\frac{S}{F}$

Dimana:

$$
\begin{array}{ll}
\text { MQ } & =\text { Marshall Quotient }(\mathrm{kg} / \mathrm{mm}) \\
\mathrm{S} & =\text { Stabilitas }(\mathrm{kg}) \\
\mathrm{F} & =\text { Nilai flow }(\mathrm{mm})
\end{array}
$$

\section{HASIL DAN PEMBAHASAN}

Dari hasil penelitian dan pengetesan benda uji menggunakan alat marshall maka didapatlah hasil sebagai berikut :

Tabel 1. Data Kadar Padas dan VIM

\begin{tabular}{|c|c|c|}
\hline \multirow{2}{*}{ No } & $\begin{array}{c}\text { Kadar } \\
\text { padas }\end{array}$ & VIM \\
\cline { 2 - 3 } & & $\%$ \\
\hline 1 & $5 \%$ & 13,69419 \\
\hline 2 & $10 \%$ & 12,32227 \\
\hline 3 & $15 \%$ & 12,07664 \\
\hline & Spesifikasi & $3-5 \%$ \\
\hline
\end{tabular}

Sumber : Analisa Pengamatan

Grafik 1. Hubungan Kadar Padas dengan VIM

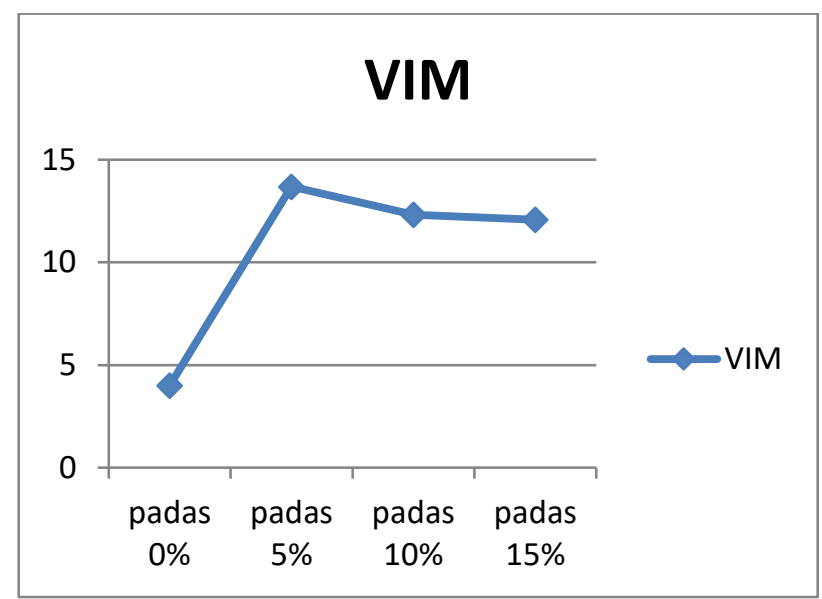

Sumber : Analisa Pengamatan

Tabel 2. Data Kadar Padas dan VMA

\begin{tabular}{|c|c|c|}
\hline \multirow{2}{*}{ No } & $\begin{array}{c}\text { Kadar } \\
\text { padas }\end{array}$ & VMA \\
\cline { 2 - 3 } & & $\%$ \\
\hline 1 & $5 \%$ & 25,75107 \\
\hline 2 & $10 \%$ & 24,57082 \\
\hline
\end{tabular}




\begin{tabular}{|c|c|c|}
\hline 3 & $15 \%$ & 24,35949 \\
\hline & Spesifikasi & $15 \%<$ \\
\hline
\end{tabular}

Sumber : Analisa Pengamatan

Grafik 2. Hubungan Kadar Padas dengan VMA

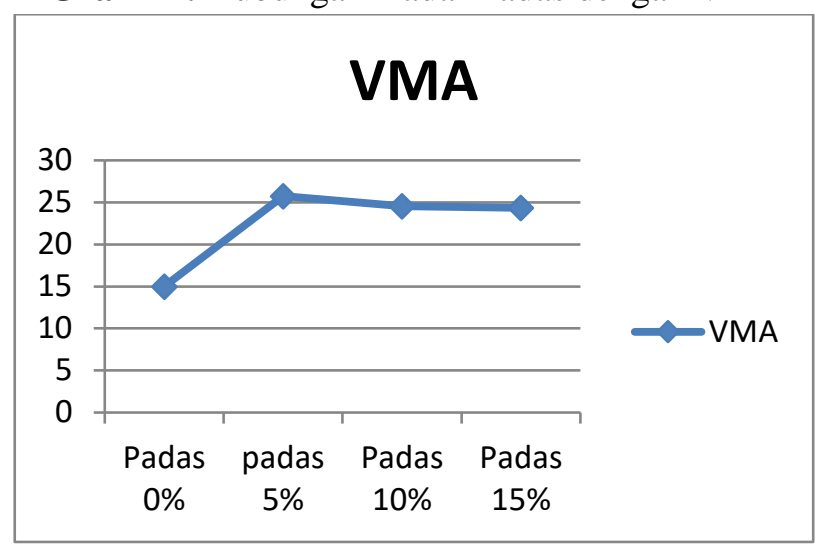

Sumber : Analisa Pengamatan

Tabel 3. Data Kadar Padas dan VFB

\begin{tabular}{|c|c|c|}
\hline \multirow{2}{*}{ No } & $\begin{array}{c}\text { Kadar } \\
\text { padas }\end{array}$ & VFB \\
\cline { 2 - 3 } & & $\%$ \\
\hline 1 & $5 \%$ & 46,8209 \\
\hline 2 & $10 \%$ & 49,84996 \\
\hline 3 & $15 \%$ & 50,42328 \\
\hline & Spesifikasi & $65 \%<$ \\
\hline
\end{tabular}

Sumber : Analisa Pengamatan

Grafik 3. Hubungan Kadar Padas dengan VFB

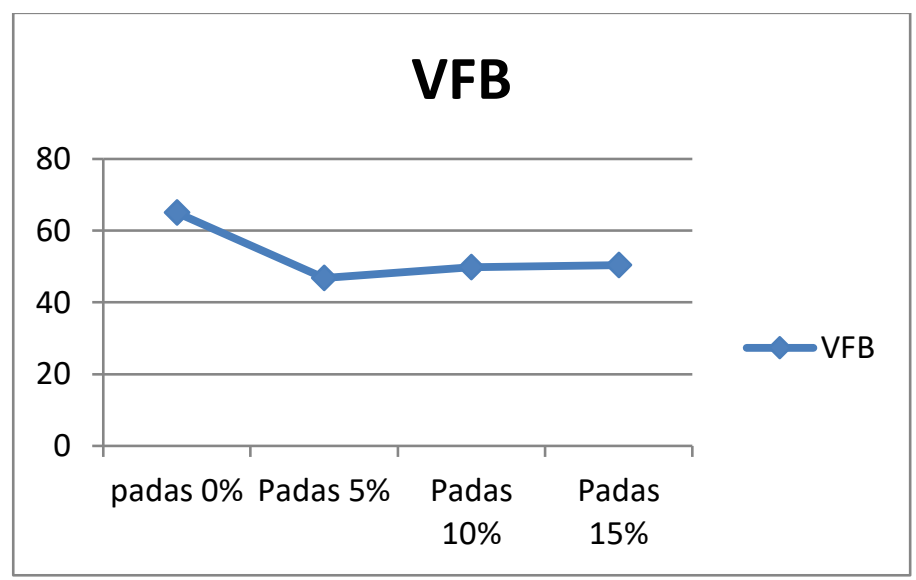

Sumber : Analisa Pengamatan 
Tabel 4. Data Kadar Padas dan Stabilitas

\begin{tabular}{|c|c|c|}
\hline \multirow{2}{*}{ No } & $\begin{array}{c}\text { Kadar } \\
\text { padas }\end{array}$ & Stabilitas \\
\cline { 2 - 3 } & & $\mathrm{Kg}$ \\
\hline 1 & $5 \%$ & 888,0747 \\
\hline 2 & $10 \%$ & 598,199 \\
\hline 3 & $15 \%$ & 441,6391 \\
\hline & Spesifikasi & $800 \mathrm{~kg}<$ \\
\hline
\end{tabular}

Sumber : Analisa Pengamatan

Grafik 4. Hubungan Kadar Padas Dengan Stabilitas

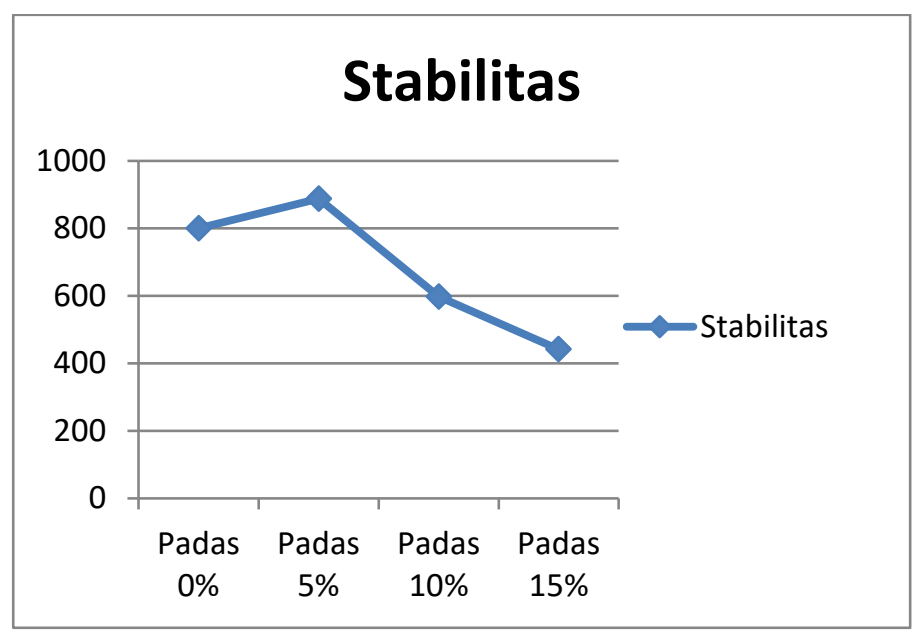

Sumber : Analisa Pengamatan

Tabel 5. Data Kadar Panas dan MQ

\begin{tabular}{|c|c|c|}
\hline \multirow{2}{*}{ No } & Kadar padas & MQ \\
\cline { 2 - 3 } & & $\mathrm{kg} / \mathrm{mm}$ \\
\hline 1 & sample $1(5 \%)$ & 381,1479 \\
\hline 2 & sample 2(5\%) & 362,4262 \\
\hline 3 & sample 3(5\%) & 350,219 \\
\hline 4 & sample $1(10 \%)$ & 224,0446 \\
\hline 5 & sample 2(10\%) & 170,2869 \\
\hline 6 & sample 3(10\%) & 226,9026 \\
\hline 7 & sample $1(15 \%)$ & 153,8812 \\
\hline 8 & sample 2(15\%) & 138,0606 \\
\hline 9 & sample 3(15\%) & 157,7601 \\
\hline & Spesifikasi & $>250$ \\
\hline
\end{tabular}

Sumber : Analisa Pengamatan 
Grafik 5. Hubungan Kadar Padas dengan MQ

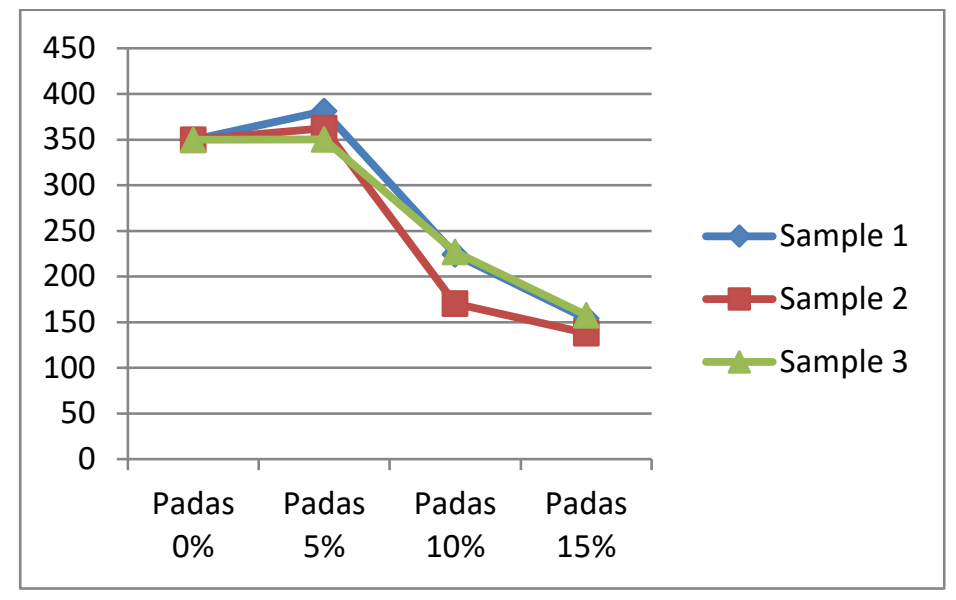

Sumber : Analisa Pengamatan

\section{KESIMPULAN}

Penelitian ini dilakukan di laboratorium fakultas teknik Universitas Kadiri dengan hasil sebagai berikut :

1. Dari hasil pengujian, untuk penambahan batu padas pada campuran aspal beton mengalami penurunan pada nilai stabilitas dan dll dari pada campuran aspal beton normal, masingmasing penurunannya dengan pemambahan batu padas yaitu antara lain 5\% sebesar $888.0747 \mathrm{~kg}, 10 \%$ sebesar $598.199 \mathrm{~kg}, 15 \%$ sebesar $441.6391 \mathrm{~kg}$.

2. Penambahan batu padas pada campuran aspal beton dengan kadar 5\%,10\% dan $15 \%$ menghasilkan volume rongga udara terhadap campuran (VIM) yaitu antara lain 13.694\%, $12.322 \%$, dan $12.077 \%$.

3. Penambahan batu padas pada campuran aspal beton dengan kadar 5\%, $10 \%$ dan $15 \%$ menghasilkan volume pori antara butir agregat (VMA) yaitu antara lain $25.751 \%, 24.570$ $\%$, dan $24.359 \%$.

4. Penambahan batu padas pada campuran aspal beton dengan kadar 5\%, $10 \%$ dan $15 \%$ menghasilkan volume pori antara butir agregat yang terisi aspal (VFB) yaitu antara lain $46.829 \%, 49.850 \%$, dan $50.423 \%$.

5. Penambahan batu padas pada campuran aspal beton dengan kadar 5\%, 10\% dan $15 \%$ menghasilkan Marshall Quotient (MQ) yaitu antara lain 381 kg/mm, 224 kg/mm, dan 154 $\mathrm{kg} / \mathrm{mm}$.

6. Untuk mencapai kadar optimum maka campuran padas pada aspal beton berkisar antara 5,5\% sampai $7,5 \%$ 
7. Dari hasil data diatas dapat disimpulkan bahwa penambahan batu padas pada campuran aspal beton tidak disarankan untuk aspal kelas 1 karena tidak sesuai dengan syarat syarat yang ditentukan.

\section{SARAN}

1. Penambahan batu padas berpengaruh terhadap nilai stabilitas.

2. Pada saat mencampurkan adonan aspal beton, sebaiknya dicampurkan secepat mungkin agar aspal tidak cepat menggumpal.

3. Penambahan batu padas sangat berpengaruh dengan kwalitas aspal yang akan digunakan.

4. Penambahan batu padas sebaiknya digunakan pada lingkup pekerjaan aspal swadaya, baik pada perkerasan kaku maupun pelebaran bahu jalan.

5. Makanya dari itu masih banyak hal yang perlu dilakukan penelitian lebih lanjut agar pada campuran aspal beton dengan tambahan batu padas dapat digunakan pada ruang lingkup pekerjaan teknik sipil yang lebih luas.

\section{UCAPAN TERIMAKASIH}

Dalam penyusunan artikel ini, penulis ucapkan terimakasih kepada dosen pembimbing dan Universitas Kadiri. Penulis berharap agar artikel ini dapat bermanfaat bagi pembaca.

\section{DAFTAR PUSTAKA}

[1] A. Y. Bintoro, A. D. Limantara, and S. Winarto, "EVALUASI KEKUATAN CONCBLOCK DENGAN AGREGAT HALUS DAN AGREGAT KASAR DARI TEMPURUNG KELAPA,”Jurmateks, vol. 1, no. 1, pp. 160-171, 2018.

[2] E. Gardjito, A. I. Candra, and Y. Cahyo, "Pengaruh Penambahan Batu Karang Sebagai Substitusi Agregat Halus Dalampembuatan Paving Block," UKaRsT, vol. 2, no. 1, p. 35, 2018, doi: 10.30737/ukarst.v2i1.374.

[3] [Kementerian PUPR]. Kementerian Pekerjaan Umum dan Perumahan Rakyat, "Perencanaan Perkerasan Jalan Beton Semen," p. 52, 2003.

[4] T. Y. Purnomo, L. D. Krisnawati, and Y. C. Sp, "KAJIAN JEMBATAN KECAMATAN SENDANG (RUAS JALAN TUGU - PABYONGAN) KABUPATEN TULUNGAGUNG DENGAN METODE KOMPOSIT," Jurmateks, vol. 1, no. 1, pp. 112$125,2018$.

[5] A. Gunarto and A. I. Candra, "Penelitian Campuran Aspal Beton Dengan Menggunakan 
Filler Bunga Pinus," UKaRsT, vol. 3, no. 1, p. 37, 2019, doi: 10.30737/ukarst.v3i1.351.

[6] B. A. Harsono, S. Winarto, and Y. C. S, "PERENCANAAN PENINGKATAN JALAN PADA RUAS JALAN PACITAN-NGADIROJO,”Jurmateks, vol. 1, no. 2, pp. 291-302, 2018.

[7] A. R. Fauzi, A. D. Limantara, and Y. C. S. P, "PEMANFAATAN LIMBAH HASIL PEMBUATAN ANYAMAN BERBAHAN BAMBU SEBAGAI CAMPURAN STANDARD MIXDESIGN PAVING BLOCK," Jurmateks, vol. 1, no. 1, pp. 137-147, 2018.

[8] I. H. Puspito, "Perencanaan Perkerasan Jalan,” 2008.

[9] S. Sukirman, Perkerasan lentur jalan raya, vol. 2. 1999.

[10] A. Kholiq, "Perencanaan Tebal Perkerasan Lentur Jalan Raya Antara Bina Marga Dan Aashto'93 (Studi Kasus: Jalan Lingkar Utara Panyingkiran-Baribis Ajalengka),” JEnsitec, vol. 1, no. 01, pp. 43-51, 2014, doi: 10.31949/j-ensitec.v1i01.15.

[11] E. Gardjito, "STUDY PERENCANAAN GEOMETRIK, PERKERASAN JALAN DAN PERENCANAAN ANGGARAN BIAYA PADA JALAN RAYA KALIDAWIR - Ds. NGUBALAN Kec. KALIDAWIR,” UKaRsT, vol. 1, no. 2, pp. 94-101, 2017, doi: 10.30737/ukarst.v1i2.264.

[12] M. E. Zakariya, "Pengaruh Penambahan Serat Sabut Kelapa Dengan Penggunaan Catalyst, Monomer, Dan Fly Ash Sebagai Material Penyusun Beton Ringan Seluler," J. Rekayasa Tek. Sipil, vol. 1, no. 1, pp. 186-194, 2018.

[13] Kimpraswil, "Spesifikasi Umum Perkerasan Aspal," 2002.

[14] Direktorat Jendral Bina Marga, "Perancangan dan pelaksanaan campuran beraspal panas bergradasi menerus (laston) menggunakan slag," no. September, 1981.

[15] G. S. Muaya, O. H. Kaseke, and M. R. E. Manoppo, "Pengaruh Terendamnya Perkerasan Aspal oleh Air Laut yang Ditinjau Terhadap Karakteristik Marshall,” J. Sipil Statik, vol. 3, no. 8, pp. 562-570, 2015.

[16] S. Sukirman, Beton Aspal Campuran Panas. 2016.

[17] AASHTO, "Standard Specifications for Transportation Materials and Methods of Sampling and Testing and AASHTO Provisional Standards," 1990.

[18] S. Sukarman, Beton Aspal Campuran Panas. Yayasan Obor Indonesia, 2003.

[19] Departmen Pekerjaan Umum, Tata Cara Pelaksanaan Lapis Aspal Beton (LASTON) Untuk Jalan Raya. 2010.

[20] D. P. Umum, "Metode pengujian campuran aspal dengan alat Marshall," SNI 06-24891991, 1991. 